OPEN ACCESS

International Journal of

Environmental Research and

Public Health

ISSN 1660-4601

www.mdpi.com/journal/ijerph

Article

\title{
Treatment of Actual Chemical Wastewater by a Heterogeneous Fenton Process Using Natural Pyrite
}

\section{Liang Sun, Yan Li and Aimin $\mathrm{Li}$ *}

State Key Laboratory of Pollution Control and Resources Reuse, School of the Environment, Nanjing University, Nanjing 210023, China; E-Mails: sunliangphd@tju.edu.cn (L.S.); liyan_0921@126.com (Y.L.)

* Author to whom correspondence should be addressed; E-Mail: liaimin@nju.edu.cn; Tel./Fax: +86-25-8968-0377.

Academic Editors: Rao Bhamidiammarri and Kiran Tota-Maharaj

Received: 14 September 2015 / Accepted: 20 October 2015 / Published: 28 October 2015

\begin{abstract}
Wastewater from chemical plants has remarkable antibiotic effects on the microorganisms in traditional biological treatment processes. An enhanced Fenton system catalyzed by natural pyrite was developed to degrade this kind of wastewater. Approximately $30 \%$ chemical oxygen demand (COD) was removed within $120 \mathrm{~min}$ when $50 \mathrm{mmol} / \mathrm{L} \mathrm{H}_{2} \mathrm{O}_{2}$ and $10 \mathrm{~g} / \mathrm{L}$ natural pyrite were used at initial $\mathrm{pH}$ from 1.8 to 7 . A BOD $/ \mathrm{COD}$ enhancement efficiency of $210 \%$ and an acute biotoxicity removal efficiency of $84 \%$ were achieved. The COD removal efficiency was less sensitive to initial $\mathrm{pH}$ than was the classic Fenton process. Excessive amounts of pyrite and $\mathrm{H}_{2} \mathrm{O}_{2}$ did not negatively affect the pyrite Fenton system. The amount of aniline generated indicated that nitrobenzene reduction by pyrite was promoted using a low initial concentration of $\mathrm{H}_{2} \mathrm{O}_{2}(<5 \mathrm{mmol} / \mathrm{L})$. Fluorescence excitation emission matrix analyses illustrated that $\mathrm{H}_{2} \mathrm{O}_{2}$ facilitated the reduction by natural pyrite of organic molecules containing an electron-withdrawing group to electron-donating group. Thus, the Fenton-like process catalyzed by pyrite can remediate wastewater containing organic pollutants under mild reaction conditions and provide an alternative environmentally friendly method by which to reuse natural pyrite.
\end{abstract}

Keywords: natural pyrite; heterogeneous Fenton process; chemical wastewater; reduction 


\section{Introduction}

Wastewater from chemical plants is a significant source of environmental contamination [1-3]. This kind of wastewater has remarkable antibiotic effects on microorganisms in traditional biological treatment processes because various organic compounds in the wastewater, especially nitro-aromatic compounds such as nitrobenzene, are toxic and bio-refractory [4,5]. Therefore, technologies that improve the biodegradability of this type of wastewater should be developed.

Various methods have been proposed to address this challenge. Physical-chemical technologies have been used to modify the chemical characteristics of wastewaters and render them treatable in biological systems without adverse effects. Advanced oxidation processes, such as Fenton reactions [6,7], ozonation [8,9], and photochemical oxidation [10,11] have shown great potential due to their high efficiency in removing refractory compounds. These technologies can mineralize contaminants completely and have been intensively investigated. In particular, the Fenton reactions have been proven to be one of the best choices for practical application because of their high efficiency, simple operation, and low cost. However, in spite of the high oxidation performance, the classic Fenton reaction (which is catalyzed by soluble $\mathrm{Fe}^{2+}$ ) has some critical limitations: The operation needs to start under low initial $\mathrm{pH}$ (the optimum $\mathrm{pH}$ usually is 3 ) and the stoichiometric quantity of soluble $\mathrm{Fe}^{2+}$ that must be added generates significant amounts of sludge [12-14]. In the last few decades, the use of iron-bearing oxides (instead of soluble $\mathrm{Fe}^{2+}$ ) as heterogeneous catalysts has received increasing attention as a means by which to overcome these drawbacks. Several studies have reported that the use of iron-bearing oxides as catalysts in Fenton reactions has advantages of low cost and easy operation, and may exhibit excellent catalysis performance in the removal of organic contaminants [15-17].

Pyrite $\left(\mathrm{FeS}_{2}\right)$ is the most abundant metal sulfide on the surface of Earth [18] and can be an appropriate material to act as a heterogeneous catalyst in the Fenton reaction. For example, Matta and Arienzo used a pyrite Fenton system for the oxidative degradation of 2,4,6-trinitrotoluene and reported that the observed degradation kinetics were much faster than those in the presence of other iron minerals such as magnetite and ferrihydrite [15,19]. Che and Bae used a pyrite Fenton system for the oxidative degradation of trichloroethylene and diclofenac, and reported that the degradation of both compounds was better in the pyrite Fenton system than in a classic Fenton system [20,21]. Wu found that hydrogen peroxide $\left(\mathrm{H}_{2} \mathrm{O}_{2}\right)$ enhanced by natural pyrite had great activity in the decoloration of azo dyes [22]. Zhang demonstrated that the degradation of nitrobenzene in the pyrite Fenton system was significantly enhanced compared to that achieved in a classic Fenton system [23].

However, there is little in the literature describing the application of the pyrite Fenton process to treat actual wastewater. The performance of this technology in remediating chemical wastewater is not yet known. Data are needed that define the catalytic performance of the pyrite Fenton process for the treatment of chemical wastewater so that the feasibility and application of this technology can be evaluated.

Meanwhile, reducing the quantity of contaminants may not necessarily be effective in reducing health and environmental risks because some degradation products may be more toxic than their parent compounds [24]. Several examples of this case have been reported in wastewater treatment processes [2,24]. Thus, information on the biodegradability and biotoxicity of chemical wastewater treated using the pyrite Fenton process is essential to evaluating the ecological safety and overall feasibility of this technology. 
In the present study, the heterogeneous Fenton process using natural pyrite has been developed. The reactivity performance of the pyrite Fenton system was compared to that of a classic Fenton system when given the same initial conditions (iron content, $\mathrm{H}_{2} \mathrm{O}_{2}$ concentration, initial $\mathrm{pH}$ ), and the effects of the dosage of pyrite and $\mathrm{H}_{2} \mathrm{O}_{2}$ on the removal of chemical oxygen demand (COD) were evaluated in detail. The biodegradability and biotoxicity of the treated wastewater were also assessed. Fluorescence excitation emission matrix (EEM) analysis was used to characterize the change of functional groups in the wastewater before and after treatment using the pyrite Fenton process. The results showed that adding a small quantity of $\mathrm{H}_{2} \mathrm{O}_{2}$ could enhance the reducing performance of the natural pyrite. The results contribute to a better understanding of the mechanism and reaction process of the pyrite Fenton technology. This report is the first to describe the reduction of nitrobenzene through Fenton oxidation catalyzed by natural pyrite.

\section{Experimental Section}

\subsection{Reagents and Wastewater}

Chemicals used in the experiments consisted of reagent grade (AR) $\mathrm{H}_{2} \mathrm{O}_{2}$ (30\%), iron (II) sulfate heptahydrate $\left(\mathrm{FeSO}_{4} \cdot 7 \mathrm{H}_{2} \mathrm{O}\right)$, sulfuric acid $\left(\mathrm{H}_{2} \mathrm{SO}_{4}, 98 \%\right)$, hydrochloric acid $(\mathrm{HCl})$, and sodium hydroxide $(\mathrm{NaOH})$ and were obtained from the Sinopharm Chemical Reagent Co. Ltd., Shanghai, China. All chemicals were used without further purification. The pyrite used in the experiments was mined from Anhui, China. The pyrite was sieved to a 300-mesh powder, washed with $1 \mathrm{~mol} \mathrm{HCl}$ to remove surface oxidation layers, rinsed three times with deoxygenated deionized water and dehydrated with ethanol, and dried and stored in a closed vial under a pure nitrogen atmosphere. Elemental analyses showed that the iron content of the pyrite was $25 \%$. The BET surface area of the pyrite was $5.960 \mathrm{~m}^{2} / \mathrm{g}$.

The wastewater samples used in experiments were collected from an industrial chemical plant located in the Jiangsu province in southeast China. The plant engages in the production of chemical intermediates for pharmaceuticals, dyes, and pesticides. The main products are $P$-nitrotoluene (PNT) and $O$-nitrotoluene (ONT). The wastewater samples were taken from the nitration process and nitrobenzene was the major by-product during the process. The characteristics of the wastewater are given in Table 1.

Table 1. Water quality indexes of wastewater used in experiments.

\begin{tabular}{cccccccc}
\hline Index & $\begin{array}{c}\text { COD } \\
(\mathbf{m g} / \mathbf{L})\end{array}$ & BOD $_{\mathbf{5}} / \mathbf{C O D}$ & $\begin{array}{c}\text { TOC } \\
(\mathbf{m g} / \mathbf{L})\end{array}$ & $\begin{array}{c}\text { Acute Biotoxicity } \\
\left(\mathbf{m g ~ Z n}^{2+} / \mathbf{L}\right)\end{array}$ & $\begin{array}{c}\text { Nitrobenzene } \\
(\mathbf{m g} / \mathbf{L})\end{array}$ & $\mathbf{p H}$ & $\begin{array}{c}\text { Conductivity } \\
(\boldsymbol{\mu S} / \mathbf{c m})\end{array}$ \\
\hline Values & $7500-8000$ & 0.1 & 2000 & $471-490$ & $>300$ & 1.8 & 38,000 \\
\hline
\end{tabular}

\subsection{Degradation of Chemical Wastewater by the Pyrite Fenton System and the Classic Fenton System}

Experiments on the pyrite Fenton and classic Fenton systems were conducted in 250-mL Erlenmeyer flasks. Chemical wastewater $(200 \mathrm{~mL})$ and a dosage of natural pyrite $(2 \mathrm{~g})$ were mixed, which was calculated to a solid-liquid ratio of $10 \mathrm{~g} / \mathrm{L}$, yielding an iron (as $\mathrm{Fe}(\mathrm{II})$ ) concentration of $2500 \mathrm{mg} / \mathrm{L}$ ( $44.64 \mathrm{mmol} / \mathrm{L})$. The degradation process was initiated by adding $1.02 \mathrm{~mL}$ of $\mathrm{H}_{2} \mathrm{O}_{2}(30 \%)$ into the flask, yielding an initial concentration of $50 \mathrm{mmol} / \mathrm{L} \mathrm{H}_{2} \mathrm{O}_{2}$, after which the resulting slurry was mixed using a mechanical stirrer $(150 \mathrm{rpm})$ at $25^{\circ} \mathrm{C}$. The classic Fenton system was operated under the same initial 
experimental conditions as for the pyrite Fenton system except $44.64 \mathrm{mmol} / \mathrm{L}$ of $\mathrm{FeSO}_{4} \cdot 7 \mathrm{H}_{2} \mathrm{O}$ was used as an aqueous iron source instead of pyrite. Experiments were conducted at various initial $\mathrm{pH}(1.8-7)$, obtained by adding diluted sulphuric acid $(10 \%)$ or sodium hydroxide solution $(5 \mathrm{~mol} / \mathrm{L})$. Samples $(1 \mathrm{~mL})$ of solution were retrieved from each reaction flask at regular intervals (every $20 \mathrm{~min}$ ) for further analysis using the techniques described below under "Analytical methods". Before the measurement of $\mathrm{COD}, \mathrm{BOD}_{5}$, acute biotoxicity, and the concentration of nitrobenzene and aniline, the $\mathrm{pH}$ of samples were adjusted to 8-9 to remove the residual aqueous solution iron and then they were aerated with $\mathrm{N}_{2}$ for 30 min to remove the residual $\mathrm{H}_{2} \mathrm{O}_{2}$. The measurement of the concentration of $\mathrm{Fe}^{2+}$, total aqueous $\mathrm{Fe}$ did not adjust the values of $\mathrm{pH}$ of samples. All experiments were performed in duplicate.

\subsection{Effects of the Dosage of Pyrite and $\mathrm{H}_{2} \mathrm{O}_{2}$}

The effects of the dosage of pyrite and $\mathrm{H}_{2} \mathrm{O}_{2}$ were investigated in batch experiments. All experiments were performed in Erlenmeyer flasks at $25{ }^{\circ} \mathrm{C}$. To observe the effects of pyrite and $\mathrm{H}_{2} \mathrm{O}_{2}$ dosages, the pyrite concentrations were set as $5,10,20$, and $50 \mathrm{~g} / \mathrm{L}$, and the $\mathrm{H}_{2} \mathrm{O}_{2}$ concentrations were set at 1,2 , $5,10,50$, and $100 \mathrm{mmol} / \mathrm{L}$. All experiments were performed in duplicate.

\subsection{Analytical Methods}

The COD concentration was measured by COD analyzer (HACH, DRB 200, Loveland, CO, USA), respectively [25]. The BOD 5 was measured by the amount of oxygen consumed by the decomposition of organic matter in wastewater over 5 days [25]. The $\mathrm{BOD}_{5} / \mathrm{COD}$ index $(\mathrm{B} / \mathrm{C})$ was used to assess the wastewater biodegradability.

The acute biotoxicity measurements were conducted using the widely used photobacterium bioassay. This method quantifies the decrease in light emission of the bioluminescent bacteria Photobacterium phosphoreum, which results from exposure to pollutants. The extent of luminescence inhibition after 5 min exposure is standardized into an equivalent concentration of $\mathrm{Zn}^{2+}$, which is used to express the degree of pollutant effects on the test bacteria. Thus, a greater luminescence inhibition corresponds to a higher equivalent $\mathrm{Zn}^{2+}$ concentration [26].

The concentration of $\mathrm{Fe}^{2+}$ was measured using to the 1,10-phenanthroline method [27]. The total aqueous Fe concentration was determined using flame atomic absorption spectrophotometry. The concentration of nitrobenzene was measured using the reduction azo-photometry [25], and the amount of aniline in the samples was determined using the $N$-(1-Naphthalene)-Ethylenediamine ( $N$-(1-naphthalenyl)-1,2-ethanediamine; $N$-na; $\mathrm{C}_{10} \mathrm{H}_{7} \mathrm{NHCH}_{2} \mathrm{CH}_{2} \mathrm{NH}_{2}$ ) method according to previous research [28].

All samples with no dilution were used for EEM analysis with Shimadzu UV-1800 ultraviolet-visible (UV/vis) spectrophotometer. The EEM fluorescence spectra were obtained as follows. The scanning field was set at an excitation wavelength from 245 to $400 \mathrm{~nm}$ and the emission wavelength from 280 to $500 \mathrm{~nm}$, with 5- and 1-nm sampling intervals in excitation (Ex) and emission (Em) modes, respectively. All fluorescence data were presented in arbitrary units. A PARAFAC analysis was used to interpret the EEM data after first completing several preparative steps (i.e., data loading, scattering removal, and initial explorative data analysis) [29-31]. 


\section{Results and Discussion}

\subsection{Comparison of COD Removal in the Pyrite Fenton System and the Classic Fenton System}

As shown in Figure 1a, at initial wastewater $\mathrm{pH}$ of 1.8 , approximately $30 \%$ of the COD was removed in the pyrite Fenton system within 120 min, whereas only $20 \%$ of the COD was removed in the classic Fenton system in the same reaction time. Figure $1 \mathrm{~b}$ shows that at the optimal initial $\mathrm{pH}$ for operation of the classic Fenton process ( $\mathrm{pH} 3$ as reported in previous papers [6]), the COD removal efficiency was greater than $30 \%$ in both Fenton systems (in $120 \mathrm{~min}$ ), but the classic Fenton system removed more COD than did the pyrite Fenton system. At an initial $\mathrm{pH}$ of 7 , the classic Fenton system did not degrade the organics of the wastewater (Figure 1c); in contrast, the COD removal efficiency was still greater than $25 \%$ in the pyrite-Fenton system.

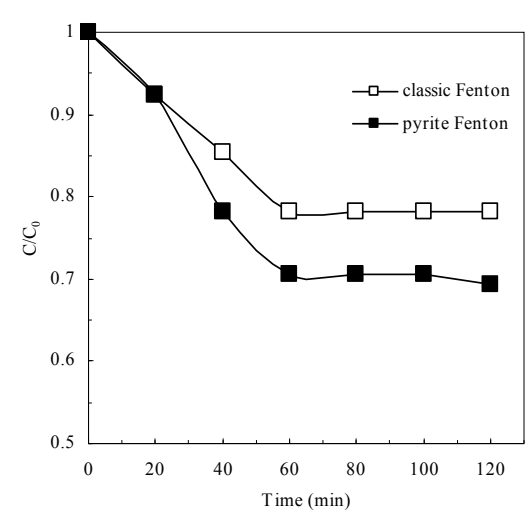

(a)

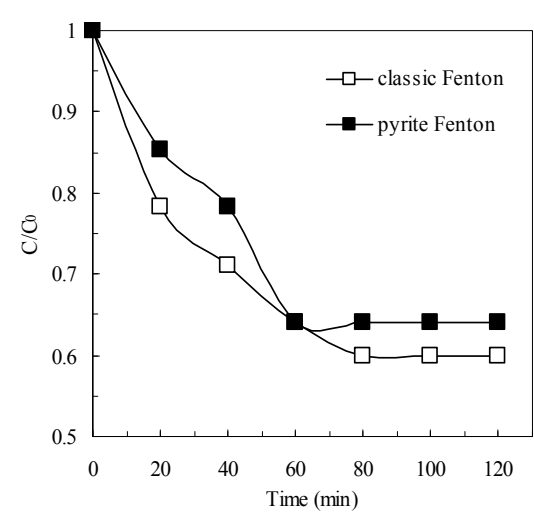

(b)

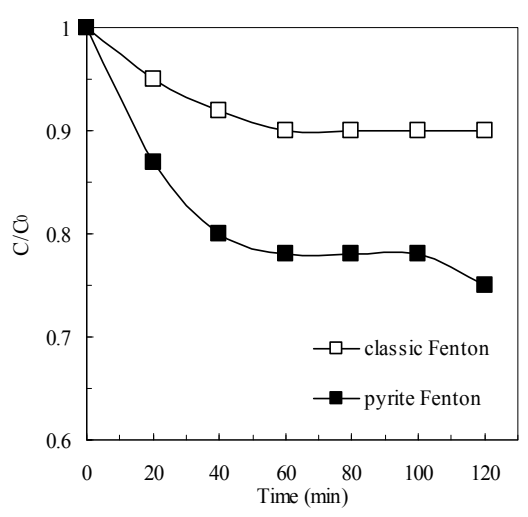

(c)

Figure 1. Comparison of pyrite Fenton and classic Fenton for the removal of COD under different initial $\mathrm{pH}$. (a) initial $\mathrm{pH}=1.8$; (b) initial $\mathrm{pH}=3$; (c) initial $\mathrm{pH}=7$. Experimental conditions: (pyrite) $)_{0}=10 \mathrm{~g} / \mathrm{L},\left(\mathrm{H}_{2} \mathrm{O}_{2}\right)_{0}=50 \mathrm{mmol} / \mathrm{L}$.

These results demonstrated that pyrite has a benefit as Fenton reaction media because the initial $\mathrm{pH}$ had little influence on the removal of organics in the pyrite Fenton process. Previous authors reported that two types of oxidation occur during the pyrite Fenton process: pyrite oxidation (Equations (1)-(3)) and Fenton oxidation (Equations (4) and (5)) [21-23].

$$
\begin{gathered}
2 \mathrm{FeS}_{2}+7 \mathrm{O}_{2}+2 \mathrm{H}_{2} \mathrm{O} \rightarrow 2 \mathrm{Fe}^{2+}+4 \mathrm{SO}_{4}{ }^{2-}+4 \mathrm{H}^{+} \\
\mathrm{FeS}_{2}+14 \mathrm{Fe}^{3+}+8 \mathrm{H}_{2} \mathrm{O} \rightarrow 15 \mathrm{Fe}^{2+}+2 \mathrm{SO}_{4}{ }^{2-}+16 \mathrm{H}^{+} \\
2 \mathrm{FeS}_{2}+15 \mathrm{H}_{2} \mathrm{O}_{2} \rightarrow 2 \mathrm{Fe}^{3+}+4 \mathrm{SO}_{4}{ }^{2-}+2 \mathrm{H}^{+}+14 \mathrm{H}_{2} \mathrm{O} \\
\mathrm{Fe}^{2+}+\mathrm{H}_{2} \mathrm{O}_{2} \rightarrow \mathrm{Fe}^{3+}+\mathrm{HO} \cdot+\mathrm{OH}^{-} \\
\mathrm{Fe}^{2+} \mathrm{OH}^{+}+\mathrm{H}_{2} \mathrm{O}_{2} \rightarrow \mathrm{Fe}^{3+} \mathrm{OH}^{2+}+\mathrm{HO} \cdot+\mathrm{OH}^{-}
\end{gathered}
$$

Mechanisms on the formation of $\mathrm{H}_{2} \mathrm{O}_{2}$ and $\mathrm{HO} \cdot$ by pyrite in oxic aqueous solutions were investigated systematically in previous studies [21-23]. In the presence of oxygen, pyrite can react to produce $\mathrm{Fe}^{2+}$ in the solution (Equation (1)), then the aqueous $\mathrm{Fe}^{2+}$ reacts with $\mathrm{H}_{2} \mathrm{O}_{2}$ to form $\mathrm{HO}$ - and changes to $\mathrm{Fe}^{3+}$ (Equation (4)). Therefore, in the pyrite Fenton system, both the generation of aqueous $\mathrm{Fe}^{2+}$ (Equation (1)) 
and of $\mathrm{HO} \cdot$ (Equation (4)) could be major rate-limiting reactions that affect the removal of wastewater COD. However, in the classic Fenton system, the generation of HO· (Equation (4)) is the only rate-limiting reaction. As shown in Figure 2, the aqueous total Fe concentration in the pyrite system gradually increased, which indicated that the aqueous $\mathrm{Fe}^{2+}$ was generated gradually. When the process was applied at the initial wastewater $\mathrm{pH}$ of 1.8 , the aqueous total Fe concentration was $725 \mathrm{mg} / \mathrm{L}$ after $120 \mathrm{~min}$ treatment. In contrast, the aqueous total Fe concentration was only $195 \mathrm{mg} / \mathrm{L}$ at an initial wastewater $\mathrm{pH}$ of 7, which resulted in less iron sludge being produced. In addition, the less iron concentration could be reduced to $21.2 \mathrm{mg} / \mathrm{L}$ after the subsequent coagulation and sedimentation process.

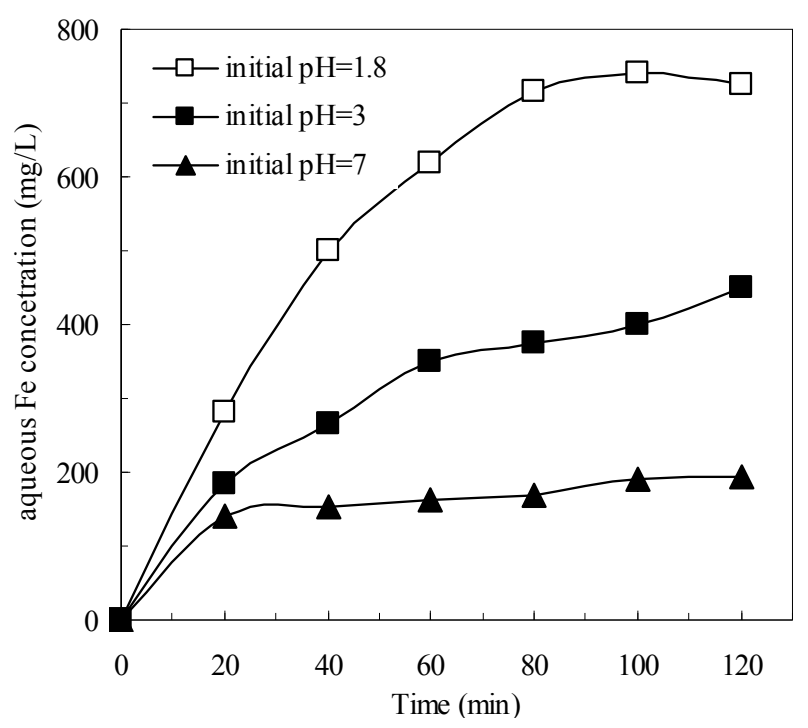

Figure 2. Aqueous Fe concentrations during the degradation in pyrite Fenton systems under different initial $\mathrm{pH}$. Experimental conditions: (pyrite $)_{0}=10 \mathrm{~g} / \mathrm{L}$, and $\left(\mathrm{H}_{2} \mathrm{O}_{2}\right)_{0}=50 \mathrm{mmol} / \mathrm{L}$.

According to Equation (4), the initial $\mathrm{pH}$ plays a key role in the removal of organics in the classic Fenton system. To avoid the precipitation of $\mathrm{Fe}(\mathrm{OH})_{3}$, which consumes $\mathrm{Fe}^{2+}$ in the aqueous solution, the classic Fenton process is always operated at $\mathrm{pH} 3$ (or lower) $[32,33]$. The present study demonstrated the validity of this conclusion. However, in the pyrite Fenton system, the COD removal efficiencies achieved at all initial $\mathrm{pH}$ values were quite similar, although the efficiency at $\mathrm{pH} 3$ was somewhat superior to that at the other $\mathrm{pH}$ values. This phenomenon can be explained by the following reasons.

As a heterogeneous material, pyrite has the primary advantage of helping to avoid the formation of iron oxide sludge [34]. Thus, pyrite can expand the effective $\mathrm{pH}$ range in which the Fenton process can operate successfully $[21,23]$. The variation of suspension $\mathrm{pH}$ with respect to time in the pyrite Fenton system is shown in Figure 3. As the reaction proceeded, the $\mathrm{pH}$ of the suspension underwent obvious changes. When the initial wastewater $\mathrm{pH}$ was extremely acidic, the $\mathrm{pH}$ slightly (within a few minutes) increased as the reaction progressed, then remained in the acidic range. In contrast, when the initial wastewater $\mathrm{pH}$ was at neutrality, the $\mathrm{pH}$ first decreased drastically from 7 to 5.5, and then gradually decreased to $\mathrm{pH}$ 4.8. As described by Equation (1), the pyrite can react with oxygen and generate protons, which is the reason that the $\mathrm{pH}$ decreased. Importantly, the decreased $\mathrm{pH}$ helped sustain the Fenton reaction. Therefore, in contrast to the classic Fenton system, the pyrite Fenton system can naturally achieve the appropriate $\mathrm{pH}$ conditions for effective Fenton reactions without the need for chemical additives. 


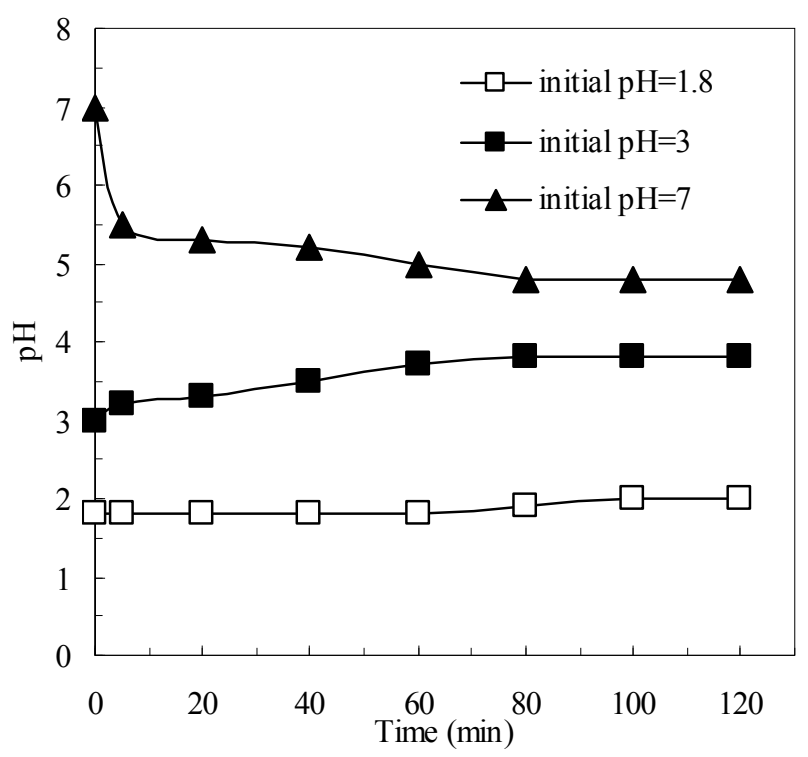

Figure 3. Variation of suspension $\mathrm{pH}$ with respect to time. Experimental conditions: (pyrite $)_{0}=10 \mathrm{~g} / \mathrm{L}$, and $\left(\mathrm{H}_{2} \mathrm{O}_{2}\right)_{0}=50 \mathrm{mmol} / \mathrm{L}$.

\subsection{Biodegradability Enhancement and Acute Biotoxicity Reduction by the Pyrite Fenton System}

To investigate the effect of biodegradability enhancement and acute biotoxicity reduction via different Fenton system, batch experiments using pyrite, zero valent iron, and magnetite were set up. The changes in the biodegradability of wastewater as a result of treatment are illustrated in Figure 4 . The B/C index of the untreated chemical wastewater was nearly 0.1 , which demonstrated that this kind of wastewater was resistant to treatment using traditional biological technologies. Neither oxidation by $\mathrm{H}_{2} \mathrm{O}_{2}$ or reduction by natural pyrite as individual processes improved the biodegradability of the wastewater remarkably. The $\mathrm{B} / \mathrm{C}$ index following $\mathrm{H}_{2} \mathrm{O}_{2}$ oxidation was 0.11 , and was 0.13 following pyrite reduction. However, after wastewater was treated using the Fenton processes, the $\mathrm{B} / \mathrm{C}$ index increased to approximately 0.3 in the classic Fenton system, to 0.31 in the pyrite Fenton system, and to 0.34 in the ZVI Fenton system, while it was only 0.23 in the magnetite Fenton system. Thus, the pyrite Fenton system showed a remarkable ability to improve wastewater biodegradability.

As shown in Figure 4, the COD efficiency of oxidation by $\mathrm{H}_{2} \mathrm{O}_{2}$ was $10 \%$ within 120 min, however, the value of BOD was decreased, suggesting that the biodegradability enhancement was mainly caused by COD removal. In the pyrite system, the COD was removed less, but the BOD was increased remarkably. The result showed that pyrite has an extremely strong reducing capacity for pollutant removal. The electron-deficient groups of compounds that include nitrobenzene could be reduced to electron-donating groups (such as aniline) to increase the biodegradability of wastewater. Comparing the results of COD removal and biodegradability enhancement of pyrite Fenton system, the biodegradability data demonstrated more remarkable changes than COD removal. These results indicated that the organic compounds were not degraded completely but were transformed to other less toxic compounds. During the Fenton process, the macromolecular compounds were split to small molecule substances by HO', and these reactions tend to simplify the structure of molecules to improve the biodegradability. 


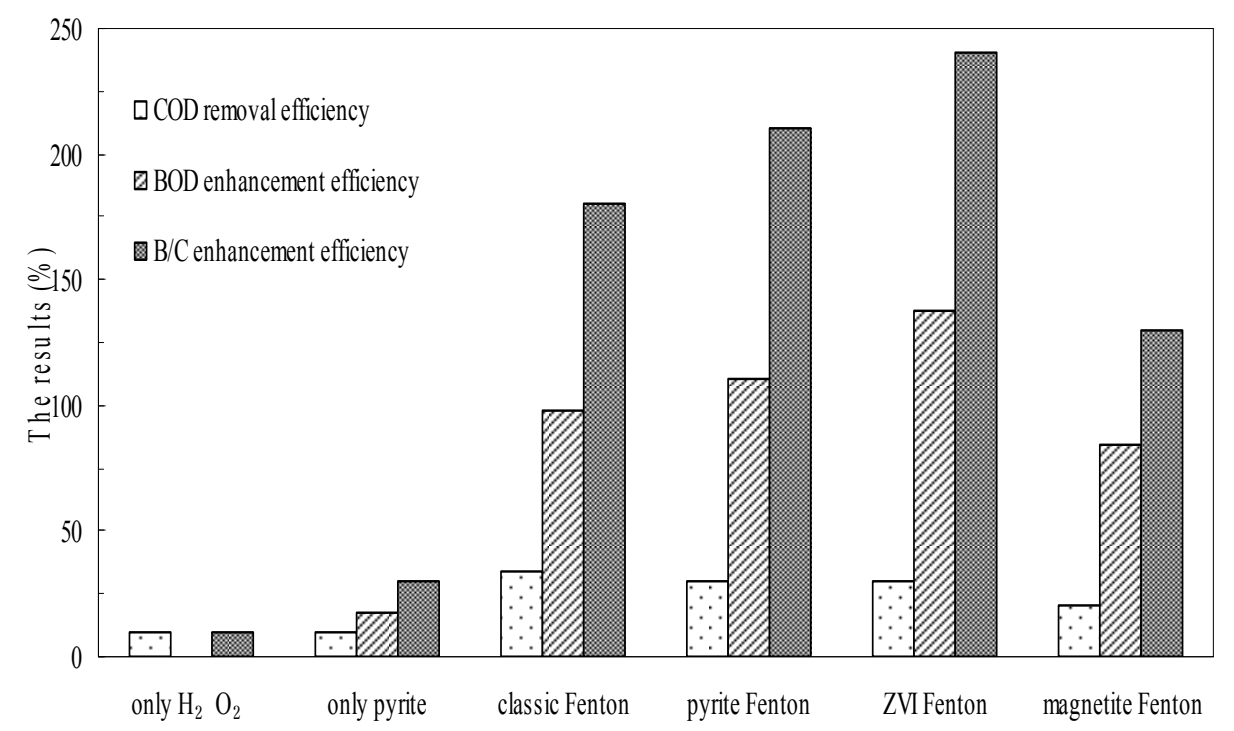

Figure 4. Comparison of pyrite Fenton and classic Fenton for the enhancement of $\mathrm{B} / \mathrm{C}$. Experimental conditions: (pyrite) $)_{0}=10 \mathrm{~g} / \mathrm{L},(\mathrm{ZVI})_{0}=10 \mathrm{~g} / \mathrm{L}$, (magnetite) $)_{0}=10 \mathrm{~g} / \mathrm{L}$, $\left(\mathrm{H}_{2} \mathrm{O}_{2}\right)_{0}=50 \mathrm{mmol} / \mathrm{L}$, and intial $\mathrm{pH}=3$.

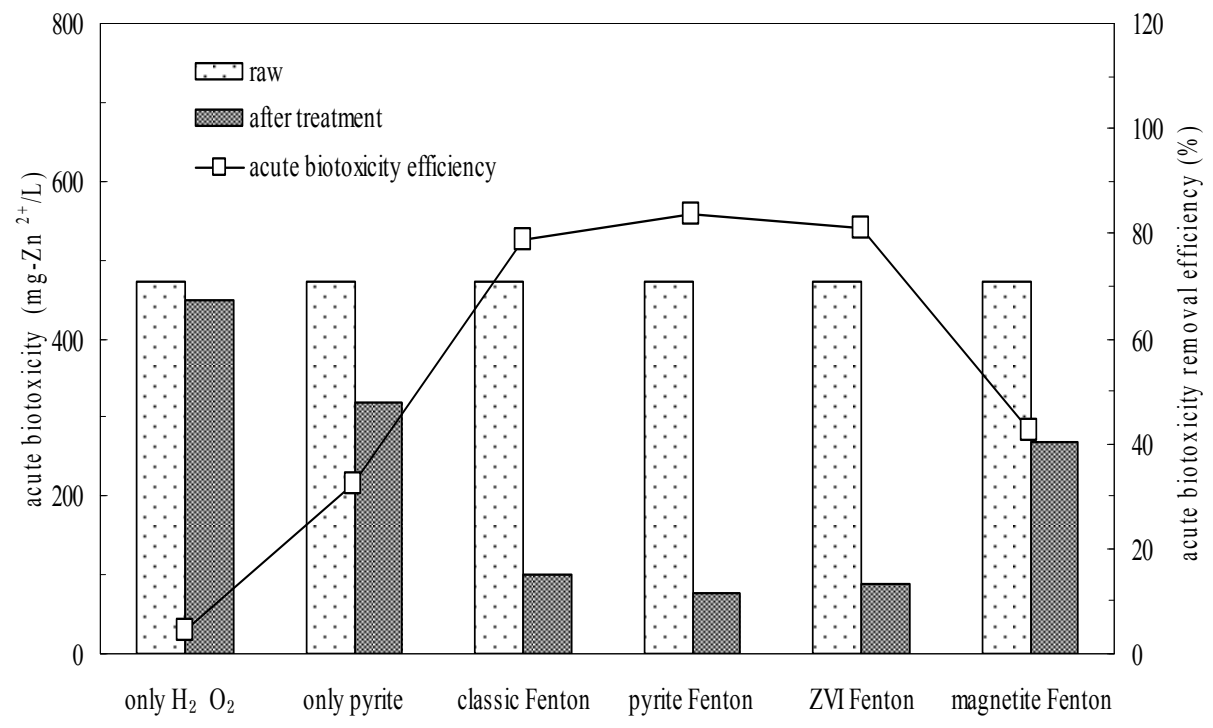

Figure 5. Comparison of pyrite Fenton and classic Fenton for the removal of acute biotoxicity. Experimental conditions: (pyrite $)_{0}=10 \mathrm{~g} / \mathrm{L},(\mathrm{ZVI})_{0}=10 \mathrm{~g} / \mathrm{L},(\text { magnetite })_{0}=10 \mathrm{~g} / \mathrm{L}$, $\left(\mathrm{H}_{2} \mathrm{O}_{2}\right)_{0}=50 \mathrm{mmol} / \mathrm{L}$, and intial $\mathrm{pH}=3$.

Batch experiments further confirmed the biotoxicity reduction effected by wastewater treatment. The acute biotoxicity values of the wastewater before and after treatment are shown in Figure 5.

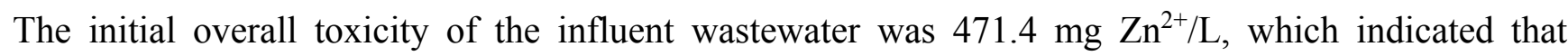
the wastewater posed a high environmental risk. As with their effects on wastewater biodegradability, neither $\mathrm{H}_{2} \mathrm{O}_{2}$ oxidation nor pyrite reduction acting alone reduced the acute biotoxicity of wastewater observably. The acute biotoxicity values of samples subjected to $\mathrm{H}_{2} \mathrm{O}_{2}$ oxidation and pyrite reduction were 450 and $320 \mathrm{mg} \mathrm{Zn}^{2+} / \mathrm{L}$, respectively. However, the acute biotoxicity values of samples were remarkably reduced to 100,77 and $90 \mathrm{mg} \mathrm{Zn}^{2+} / \mathrm{L}$ after the classic Fenton, pyrite Fenton and ZVI Fenton

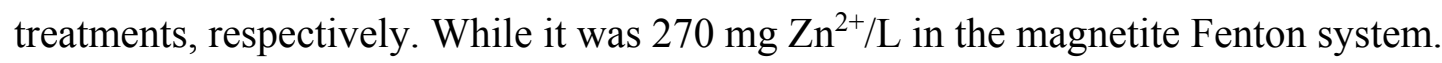


The results indicated that the magnetite Fenton system can not significantly improve the biodegradability and reduce the biotoxicity of chemical wastewater, while both the pyrite Fenton and ZVI Fenton technologies are the novel alternative to the classic Fenton process for simultaneously improving the biodegradability and reducing the biotoxicity.

\subsection{Effects of the Pyrite and $\mathrm{H}_{2} \mathrm{O}_{2}$ on the Removal of Organics in the Pyrite Fenton System}

The effect of natural pyrite dosage on the removal of pollutants was examined in batch experiments using different initial dosages of pyrite $(0-50 \mathrm{~g} / \mathrm{L})$. The results are shown in Figure 6 . Within 120 min, the COD removal efficiency reached $10 \%, 20 \%, 36 \%, 32 \%$, and $26 \%$ at pyrite dosages of $0,5,10,20$, and $50 \mathrm{~g} / \mathrm{L}$, respectively. These results indicated that COD removal increased significantly as the initial pyrite concentration increased from $0 \mathrm{~g} / \mathrm{L}$ to $10 \mathrm{~g} / \mathrm{L}$, whereas COD removal decreased slightly as the initial pyrite concentrations increased from $20 \mathrm{~g} / \mathrm{L}$ to $50 \mathrm{~g} / \mathrm{L}$. Based on these results, a pyrite dosage of $10 \mathrm{~g} / \mathrm{L}$ was optimal for the pyrite Fenton system treating the particular wastewater used in the experiments. This variation in COD removal as a function of pyrite dosage probably can be attributed to the follow reason.

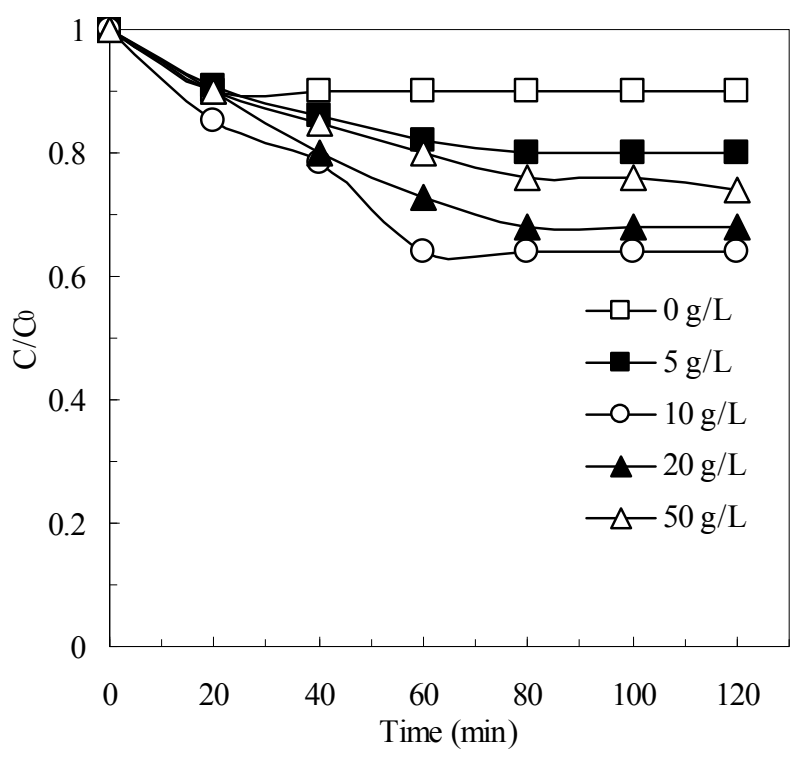

Figure 6. The effect of pyrite dosage on the removal of COD in pyrite Fenton system. Experimental conditions: $\left(\mathrm{H}_{2} \mathrm{O}_{2}\right)_{0}=50 \mathrm{mmol} / \mathrm{L}$, and initial $\mathrm{pH}=3$.

According to Equations (1)-(3), increasing the amount of pyrite in suspension proportionally increases the aqueous $\mathrm{Fe}^{2+}$ concentration, which improves $\mathrm{HO} \cdot$ formation (Equation (4)) and enhances the degradation of organics. However, previous authors pointed out that an excessive amount of aqueous $\mathrm{Fe}^{2+}$ in a pyrite suspension may promote the unwanted consumption of HO- (as shown in Equation (6)), which can negatively affect the oxidative degradation of COD by Fenton reactions $[21,22,32]$.

$$
\mathrm{Fe}^{2+}+\mathrm{HO} \rightarrow \mathrm{Fe}^{3+}+\mathrm{OH}^{-}
$$

Figure 7 shows the effect of the initial $\mathrm{H}_{2} \mathrm{O}_{2}$ concentrations on the removal of COD in the pyrite Fenton system. When the initial $\mathrm{H}_{2} \mathrm{O}_{2}$ was $1 \mathrm{mmol} / \mathrm{L}$, the removal efficiency of COD was $15 \%$ after $120 \mathrm{~min}$, but at an initial $\mathrm{H}_{2} \mathrm{O}_{2}$ concentration of $50 \mathrm{mmol} / \mathrm{L}$, this efficiency increased to $36 \%$. However, 
the TOC removal efficiency was only $10 \%$ under this condition. The results indicated that the organic compounds contained in the wastewater were not degraded completely but were split to small molecule substances by $\mathrm{HO}$. The stoichiometric amount of $\mathrm{H}_{2} \mathrm{O}_{2}$ for the complete mineralization of the carbon content to $\mathrm{CO}_{2}$ and $\mathrm{H}_{2} \mathrm{O}$ following Equation (7) was calculated to $33.33 \mathrm{mmol} / \mathrm{L}$. It is clear that the actual dosage of $\mathrm{H}_{2} \mathrm{O}_{2}$ is more than the calculated value. Segura et al. also found this phenomenon in zero valent iron Fenton system [35]. They illustrated that the increase of the $\mathrm{H}_{2} \mathrm{O}_{2}$ showed a clear enhancement of performance when the highest oxidant loading $\left(200 \% \mathrm{H}_{2} \mathrm{O}_{2}\right)$ was used. However, when the initial $\mathrm{H}_{2} \mathrm{O}_{2}$ increased to $100 \mathrm{mmol} / \mathrm{L}$, the COD remove efficiency decreased to 30 .

$$
\mathrm{C}+2 \mathrm{H}_{2} \mathrm{O}_{2} \rightarrow \mathrm{CO}_{2}+2 \mathrm{H}_{2} \mathrm{O}
$$

These variations were consistent with those observed in previous studies [6,36], which proposed that when an appropriate concentration of $\mathrm{Fe}^{2+}$ was provided in the reaction system, an increase of the $\mathrm{H}_{2} \mathrm{O}_{2}$ concentration could enhance the oxidative degradation of organics in the pyrite Fenton system due to the improvement in $\mathrm{HO}$ - formation. In contrast, an excessive amount of $\mathrm{H}_{2} \mathrm{O}_{2}$ in a pyrite suspension readily reacts with generated $\mathrm{HO} \cdot($ Equation (8)), reducing the oxidative removal of COD by $\mathrm{HO}$.

$$
\mathrm{H}_{2} \mathrm{O}_{2}+\mathrm{HO} \cdot \rightarrow \mathrm{OOH} \cdot+\mathrm{H}_{2} \mathrm{O}
$$

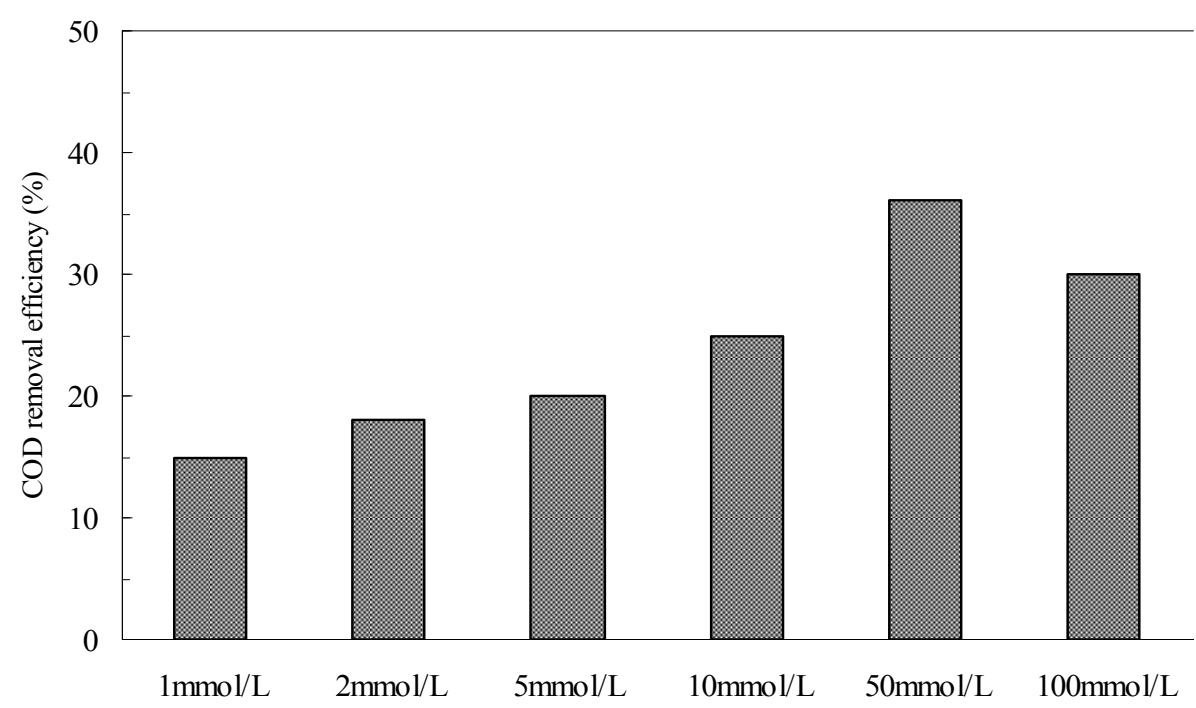

Figure 7. The effect of $\mathrm{H}_{2} \mathrm{O}_{2}$ concentrations on the removal of COD in pyrite Fenton system. Experimental conditions: (pyrite) $0=10 \mathrm{~g} / \mathrm{L}$, and initial $\mathrm{pH}=3$.

However, neither of the potentially negative effects posed by excessive amounts of pyrite and $\mathrm{H}_{2} \mathrm{O}_{2}$ appeared to be significant in the pyrite Fenton system. Relative insensitivity to such effects was another advantage that the pyrite Fenton system offered over the classic Fenton system.

\subsection{The Generation of Aniline in the Pyrite Fenton System}

Figure 8 shows the influence of initial $\mathrm{H}_{2} \mathrm{O}_{2}$ concentration on the generation of aniline. The untreated wastewater did not contain aniline, and no aniline was generated in the classic Fenton process. In the pyrite Fenton system, when only pyrite was added, the concentration of aniline in the treated wastewater was $18.7 \mathrm{mg} / \mathrm{L}$ after $120 \mathrm{~min}$, which indicated that the natural pyrite could have a reduction capacity for 
nitro-aromatic compounds. In response to $\mathrm{H}_{2} \mathrm{O}_{2}$, within 120 min the concentration of aniline reached 23.4, 37.5, 9.4, and $3.7 \mathrm{mg} / \mathrm{L}$ at initial $\mathrm{H}_{2} \mathrm{O}_{2}$ concentrations of $1,2,5$, and $10 \mathrm{mmol} / \mathrm{L}$, respectively. However, when the initial $\mathrm{H}_{2} \mathrm{O}_{2}$ concentration was $50 \mathrm{mmol} / \mathrm{L}$, no aniline was detected in the aqueous solution. These results showed that low initial concentrations of $\mathrm{H}_{2} \mathrm{O}_{2}$ (from $1 \mathrm{mmol} / \mathrm{L}$ to $2 \mathrm{mmol} / \mathrm{L}$ ) significantly improved the reduction performance of pyrite, whereas high concentrations of $\mathrm{H}_{2} \mathrm{O}_{2}$ ( $5 \mathrm{mmol} / \mathrm{L}$ to $50 \mathrm{mmol} / \mathrm{L}$ ) inhibited the reduction performance.

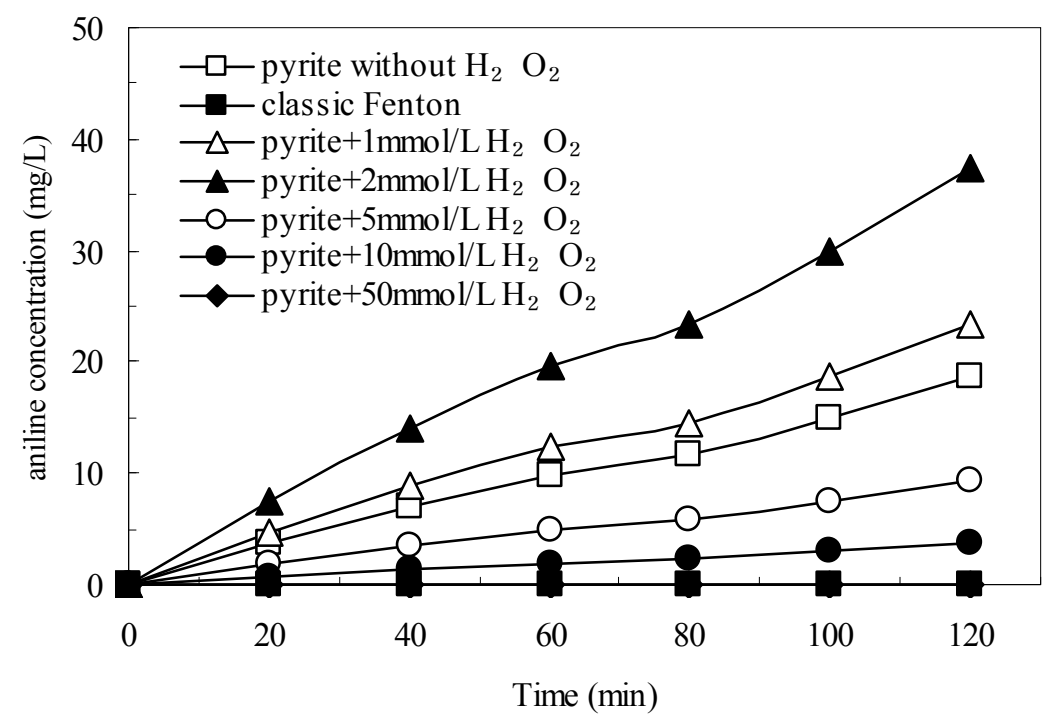

Figure 8. Amount of aniline in the aqueous solution with different initial $\mathrm{H}_{2} \mathrm{O}_{2}$ concentration. Experimental conditions: (pyrite) $)_{0}=10 \mathrm{~g} / \mathrm{L}$, and initial $\mathrm{pH}=1.8$.

Stumm and James proposed that the dissociation of pyrite releases dissolved ferrous and sulfur $\left(\mathrm{S}_{2}{ }^{2-}\right)$ ions, which have an extremely strong reducing capacity for pollutant removal (Equation (9)) [37]. Zhang also found that the released dissolved ferrous effectively made pyrite an electron donor that resulted in the formation of $\mathrm{Fe}^{3+}$, whereas the nitro group of compounds that include nitrobenzene were electron-deficient and thus, they could be readily reduced [34].

$$
\mathrm{FeS}_{2} \rightarrow \mathrm{Fe}_{(\mathrm{aq})}{ }^{2+}+\mathrm{S}_{2(\mathrm{aq})}{ }^{2-}
$$

Many studies have suggested that the decomposition of $\mathrm{H}_{2} \mathrm{O}_{2}$ can be controlled by surface-catalyzed process in the heterogeneous reaction involving iron oxides (e.g., magnetite, goethite, and hematite) [38,39]. Kong pointed out that the oxygen and $\mathrm{H}_{2} \mathrm{O}_{2}$ in an aqueous solution could oxidize the surface $\mathrm{Fe}(\mathrm{II})$ of pyrite to Fe(III), as described in Equations (10) and (11) [40]. Kwan found that most organics in the heterogeneous Fenton process were degraded by $\mathrm{HO} \cdot$ produced from dissolved $\mathrm{Fe}^{2+}$ (Equation (4)), not by a surface-catalyzed process (Equation (10)) [41]. Bae also observed this phenomenon in the pyrite Fenton system and furthermore demonstrated that $\mathrm{H}_{2} \mathrm{O}_{2}$ could reduce the surface Fe(III) of pyrite to $\mathrm{Fe}(\mathrm{II})$, and that the regenerated $\mathrm{Fe}(\mathrm{II})$ could be released into the aqueous solution and react with $\mathrm{H}_{2} \mathrm{O}_{2}$ to produce $\mathrm{HO} \cdot($ Equation (4)), which could react with target contaminants [21].

$$
\begin{gathered}
\mathrm{Fe}_{\text {pyrite }}^{\text {II }}+\mathrm{O}_{2} \rightarrow \mathrm{Fe}_{\text {pyrite }}{ }^{\mathrm{III}}+\mathrm{O}_{2}^{-} \\
\mathrm{Fe}_{\text {pyrite }}{ }^{\mathrm{II}}+\mathrm{H}_{2} \mathrm{O}_{2} \rightarrow \mathrm{Fe}_{\text {pyrite }}{ }^{\mathrm{III}}+\mathrm{HO} \cdot+\mathrm{OH}^{-}
\end{gathered}
$$




$$
\mathrm{Fe}_{\text {pyrite }}{ }^{\text {III }}+\mathrm{H}_{2} \mathrm{O}_{2} \rightarrow \mathrm{Fe}_{\text {pyrite }}{ }^{\text {II }}+\mathrm{OOH} \cdot+\mathrm{H}^{+}
$$

The pathway of this reaction process is shown in Figure 9. According to Equation (12), $\mathrm{H}_{2} \mathrm{O}_{2}$ can reduce the surface $\mathrm{Fe}$ (III) of pyrite to $\mathrm{Fe}$ (II) and enhance the generation of aqueous $\mathrm{Fe}^{2+}$. When the initial concentration of $\mathrm{H}_{2} \mathrm{O}_{2}$ is low (such as $1 \mathrm{mmol} / \mathrm{L}$ and $2 \mathrm{mmol} / \mathrm{L}$ ), the residual $\mathrm{H}_{2} \mathrm{O}_{2}$ in the aqueous solution cannot oxidize the aqueous $\mathrm{Fe}^{2+}$ thoroughly; hence, there is ample aqueous $\mathrm{Fe}^{2+}$ to join in the reduction of nitrobenzene compounds to aniline. In the present study, aqueous $\mathrm{Fe}^{2+}$ concentrations reached 198 and $187 \mathrm{mg} / \mathrm{L}$ in the pyrite Fenton system (after $120 \mathrm{~min}$ ) at initial $\mathrm{H}_{2} \mathrm{O}_{2}$ concentrations of 1 and $2 \mathrm{mmol} / \mathrm{L}$, respectively. However, when the initial $\mathrm{H}_{2} \mathrm{O}_{2}$ concentration was sufficient (greater than $10 \mathrm{mmol} / \mathrm{L}$ ), the aqueous $\mathrm{Fe}^{2+}$ was oxidized by the excess $\mathrm{H}_{2} \mathrm{O}_{2}$, indicating that Fenton oxidization is the main reaction that occurs during the entire process. In fact, the mechanism and entire process of the pyrite Fenton technology is complex and not very explicit. Further investigation of the reductive transformations and oxidative pollutant degradation that occurs in the pyrite Fenton system is ongoing.

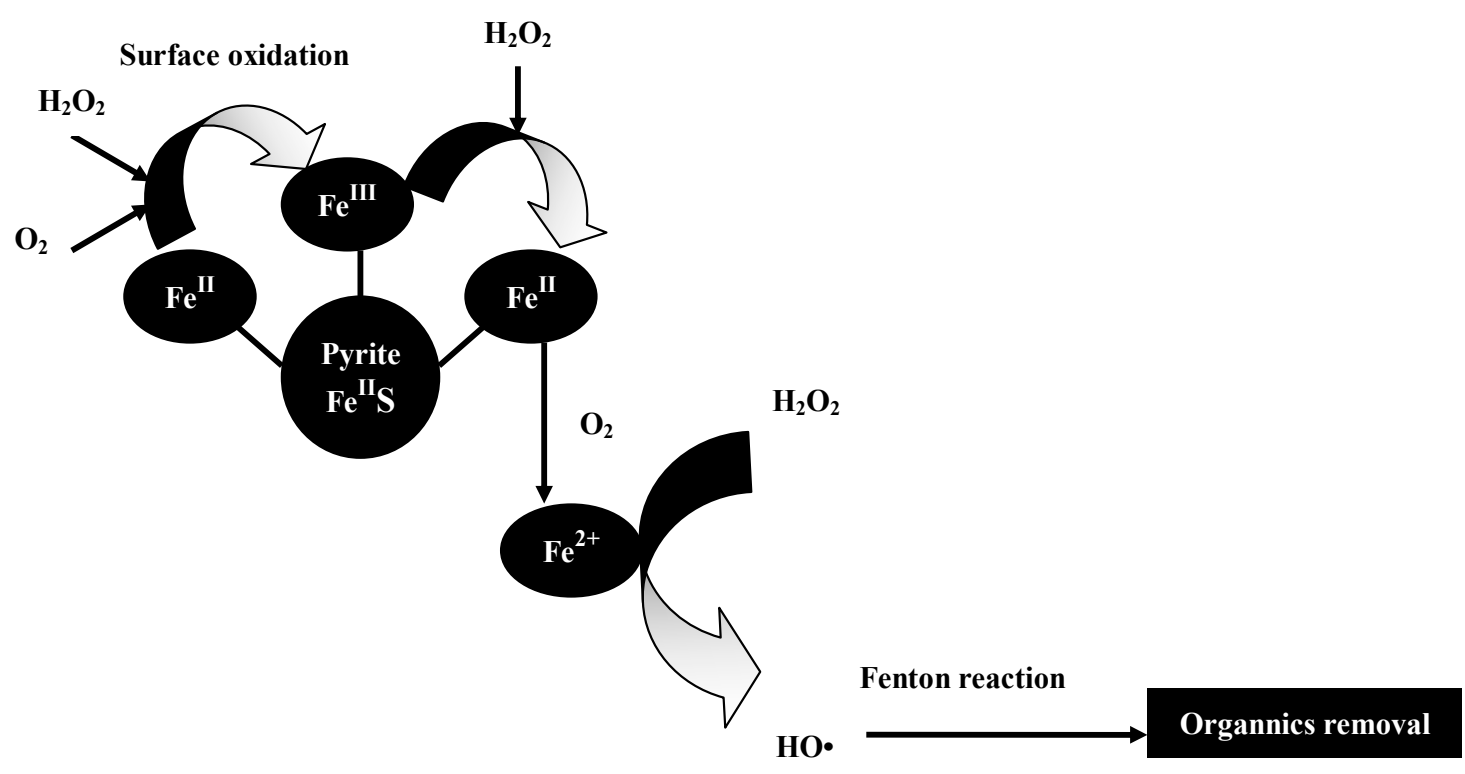

Figure 9. Proposed pathway for oxidative degradation of organics by pyrite Fenton system.

\subsection{Evaluation of Organic Functional Groups by EEM in the Pyrite Fenton System}

EEM has been frequently used to characterize organics in water and wastewater treatment systems due to its high sensitivity, good selectivity, and non-destructive effect on samples [42,43]. As a technique of multivariate data analysis, PARAFAC can mathematically decompose the complex fluorescence spectra into individual fluorescent components for both quantitative and qualitative analysis $[44,45]$. In the present study, the EEM-PARAFAC analysis method was used to evaluate the organic functional groups in the wastewater before and after it was subjected to classic Fenton and pyrite Fenton treatment. 


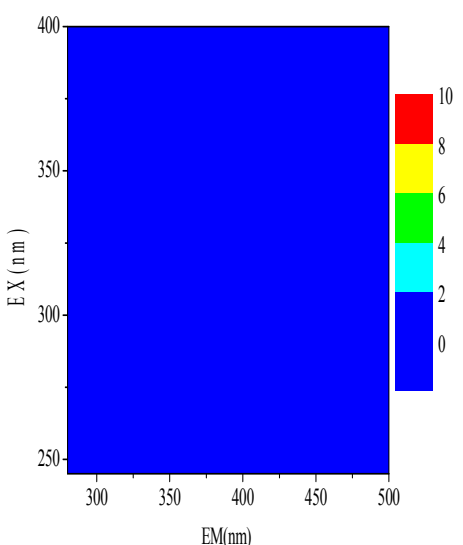

(a)

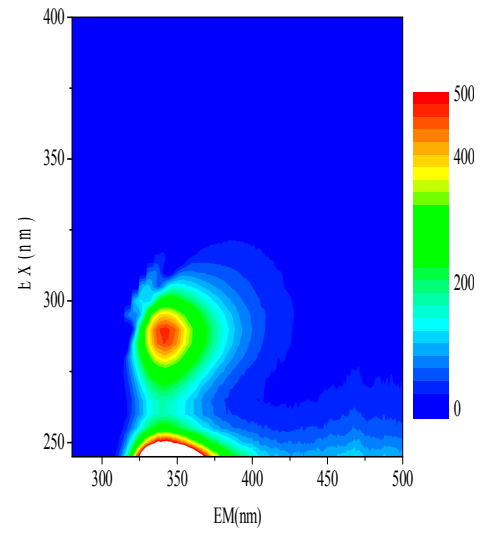

(d)

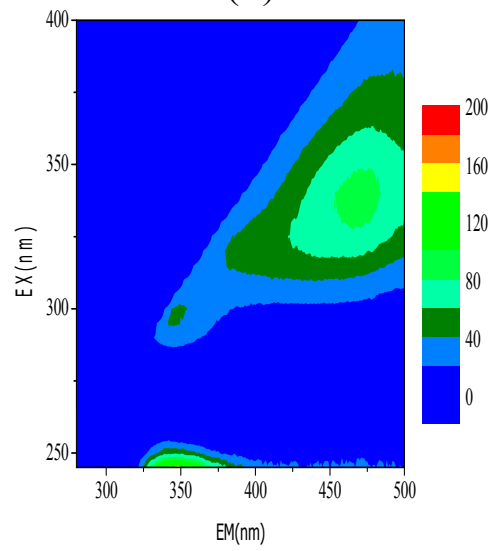

(g)

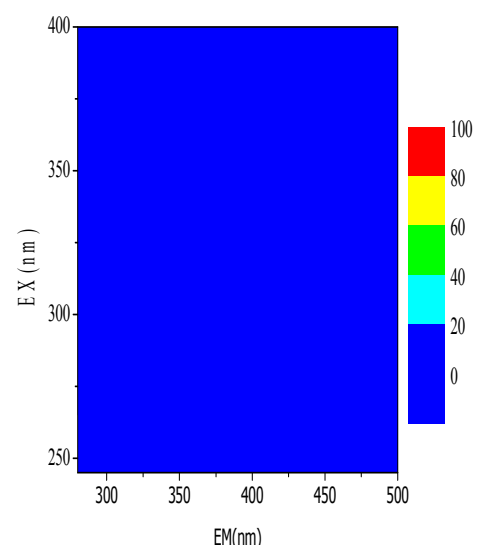

(b)

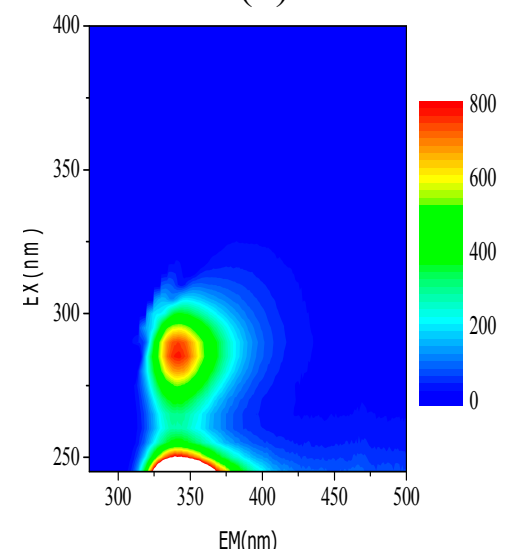

(e)

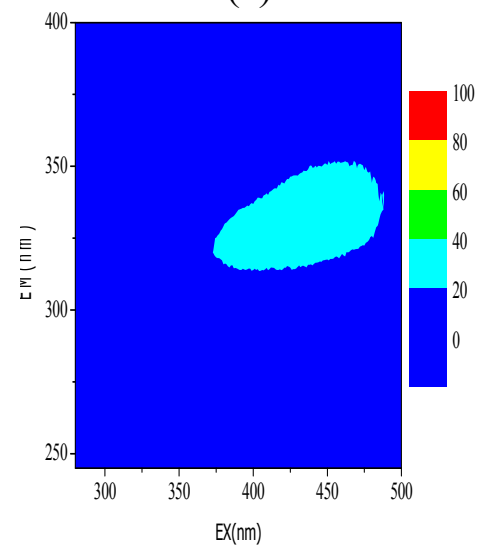

(h)

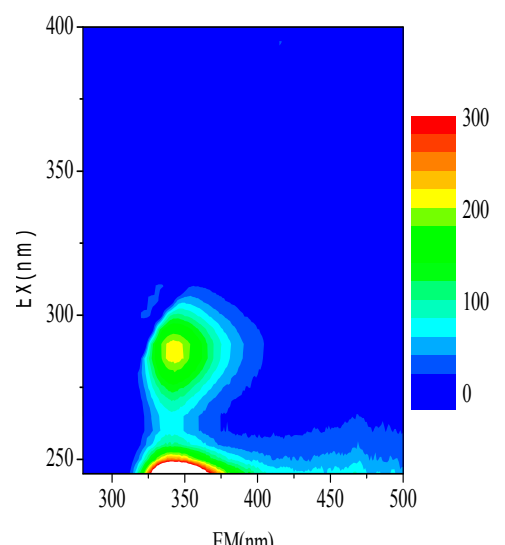

(c)

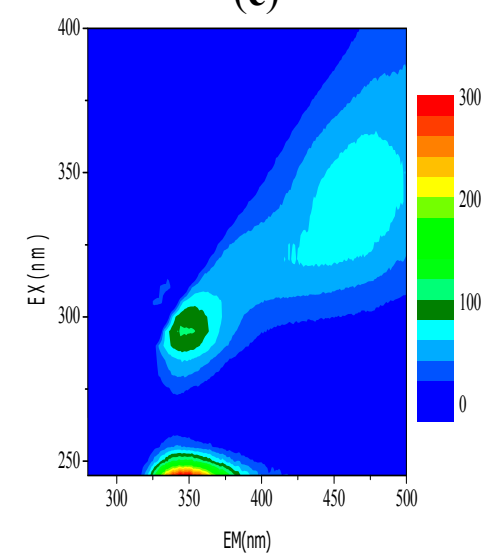

(f)

Figure 10. Sample results scanned by three-dimensional fluorescence. (a) raw water; (b) classic Fenton; (c) pyrite without $\mathrm{H}_{2} \mathrm{O}_{2}$; (d) pyrite +1 mmol/ $\mathrm{L} \mathrm{H}_{2} \mathrm{O}_{2}$; (e) pyrite $+2 \mathrm{mmol} / \mathrm{L}$ $\mathrm{H}_{2} \mathrm{O}_{2} ;$ (f) pyrite $+5 \mathrm{mmol} / \mathrm{L} \mathrm{H}_{2} \mathrm{O}_{2} ;$ (g) pyrite $+10 \mathrm{mmol} / \mathrm{L} \mathrm{H}_{2} \mathrm{O}_{2} ;$ (h) pyrite $+50 \mathrm{mmol} / \mathrm{L} \mathrm{H}_{2} \mathrm{O}_{2}$.

Figure 10 shows the three-dimensional fluorescence spectra for various samples. Using the peak-picking function of the instrument's FL solution software, no peaks were found in the EEM spectra from either the raw (i.e., untreated) wastewater or from wastewater treated using the classic Fenton process (Figure 10a,b); this indicated that there were no electron-donating groups contained in these samples. One major peak was found in the spectra from a number of samples at approximately Ex $290 \mathrm{~nm}$ and Em $432 \mathrm{~nm}$ (Figure 10c-g). The relative heights of the peaks for each sample were calculated to 211.1, 471.9, 772.2, 102.3, and 41.87, respectively. No spectral peak was observed for the sample 
that included pyrite and $50 \mathrm{mmol} / \mathrm{L} \mathrm{H}_{2} \mathrm{O}_{2}$ (Figure 10h). Generally, fluorescent peaks at Ex $290 \mathrm{~nm}$ and Em $432 \mathrm{~nm}$ originate from amine groups $\left(-\mathrm{NH}_{2}\right)$, and the height of a peak corresponds with the quantity of organic material that contains amine groups (such as aniline) [46]. The spectral responses shown in Figure 10 indicated that low initial $\mathrm{H}_{2} \mathrm{O}_{2}$ concentrations facilitated the reduction of organic molecules containing electron-withdrawing groups (such as $-\mathrm{NO}_{2}$ ) to electron-donating groups (such as $-\mathrm{NH}_{2}$ ) by pyrite. These results proposed that increased $\mathrm{H}_{2} \mathrm{O}_{2}$ concentration could enhance the reduction of nitrobenzene in a pyrite Fenton system by improving the surface Fe(II) regeneration.

\section{Conclusions}

In this research, the treatment of actual chemical wastewater using an enhanced Fenton system catalyzed by natural pyrite was evaluated systematically. The results shows that the Fenton process catalyzed using natural pyrite effectively removes COD across a broad range of initial $\mathrm{pH}$ (pH 1.8 to 7). Furthermore, the pyrite Fenton process effectively increases the biodegradability of treated wastewater and simultaneously reduces the toxicity of treated wastewater. Compared to that of the classic Fenton process, the COD removal efficiency of the pyrite Fenton process is less sensitive to the initial solution $\mathrm{pH}$ and relatively insensitive to excessive amounts of both pyrite and $\mathrm{H}_{2} \mathrm{O}_{2}$. Finally, in the pyrite Fenton system, the reduction of nitrobenzene and organic molecules containing electron-withdrawing groups to electron-donating groups by natural pyrite can be promoted by adding a small amount of $\mathrm{H}_{2} \mathrm{O}_{2}$ (initial concentration $<5 \mathrm{mmol} / \mathrm{L}$ ). Thus, the pyrite Fenton process offers several operational advantages over the classic Fenton process and is a viable method by which to remediate organic pollutants in wastewater, while providing an environmentally friendly alternative for reusing natural pyrite.

\section{Acknowledgments}

We gratefully acknowledge the generous support provided by the Nation Water Pollution Control and Management of major special science and technology of China (No. 2015ZX07204002) and the National Natural Science Foundation of China (NO. 51408295), China.

\section{Author Contributions}

All authors were involved in discussing the ideas and designing this study. Sun Liang drafted the manuscript. Li Yan and Li Aimin edited draft versions and finalized the manuscript. All the authors have read and approved the final manuscript.

\section{Conflicts of Interest}

The authors declare no conflict of interest.

\section{References}

1. Fan, J.H.; Ma, L.M. The pretreatment by the $\mathrm{Fe}-\mathrm{Cu}$ process for enhancing biological degradability of the mixed wastewater. J. Hazard. Mater. 2009, 164, 1392-1397.

2. Sun, L.; Wang, C.; Ji, M.; Kong, X. Treatment of mixed chemical wastewater and the agglomeration mechanism via an internal electrolysis filter. Chem. Eng. J. 2013, 215-216, 50-56. 
3. Wu, C.Y.; Zhou, Y.X.; Wang, P.C.; Guo, S.J. Improving hydrolysis acidification by limited aeration in the pretreatment of petrochemical wastewater. Bioresour. Technol. 2015, 194, 256-262.

4. Ren, C.X.; Li, Y.M.; Li, J.F.; Sheng, G.D.; Hu, L.J.; Zheng, X.M. Immobilization of nanoscale zero valent iron on organobentonite for accelerated reduction of nitrobenzene. J. Chem. Technol. Biotechnol. 2014, 89, 1961-1966.

5. Yin, W.Z.; Wu, J.H.; Huang, W.L.; Wei, C.H. Enhanced nitrobenzene removal and column longevity by coupled abiotic and biotic processes in zero-valent iron column. Chem. Eng. J. 2015, 259, 417-423.

6. Chamarro, E.; Marco, A.; Esplugas, E. Use of Fenton reagent to improve organic chemical biodegradability. Water Res. 2001, 35, 1047-1051.

7. Canizares, P.; Paz, R.; Saez, C.; Rodrigo, M.A. Costs of the electrochemical oxidation of wastewaters: A comparison with ozonation and Fenton oxidation processes. J. Environ. Manag. 2009, 90, 410-420.

8. Dariush, S.; Moheb A.; Abbas R.; Larouk S.; Roy R.; Azzouz A. Total mineralization of sulfamethoxazole and aromatic pollutants through $\mathrm{Fe}(2+)$-montmorillonite catalyzed ozonation. J. Hazard. Mater. 2015, 298, 338-350.

9. Nakai, S.; Okuda, T.; Okada, M. Production of mono-and di-carboxylated polyethylene glycols as a factor obstacle to the successful ozonation-assisted biodegradation of ethoxylated compounds. Chemosphere 2015, 136, 153-159.

10. Kaur, M.; Verma, A.; Rajput, H. Potential use of foundry sand as heterogeneous catalyst in solar photo-fenton degradation of herbicide isoproturon. Int. J. Environ. Res. 2015, 9, 85-92.

11. Doumic, L.I.; Soares, P.A.; Ayude, M.A.; Cassanello, M.; Boaventura, R.A.R.; Vilar, V.J.P. Enhancement of a solar photo-Fenton reaction by using ferrioxalate complexes for the treatment of a synthetic cotton-textile dyeing wastewater. Chem. Eng. J. 2015, 277, 86-96.

12. Che, H.; Lee, W. Selective redox degradation of chlorinated aliphatic compounds by Fenton reaction in pyrite suspension. Chemosphere 2011, 82, 1103-1108.

13. Huang, R.; Fang, Z.; Yan, X.; Cheng, W. Heterogeneous sono-Fenton catalytic degradation of bisphenol $\mathrm{A}$ by $\mathrm{Fe}_{3} \mathrm{O}_{4}$ magnetic nanoparticles under neutral condition. Chem. Eng. J. 2012, 197, 242-249.

14. Masomboon, N.; Ratanatamskul, C.; Lu, M.C. Chemical oxidation of 2,6-dimethylaniline in the Fenton process. Environ. Sci. Technol. 2009, 43, 8629-8634.

15. Matta, R.; Hanna, K.; Chiron, S. Fenton-like oxidation of 2,4,6-trinitrotoluene using different iron minerals. Sci. Total. Environ. 2007, 385, 242-251.

16. Maria, A.F.D.; Emilio, R.; María, F.F.; Marta, P.; Maria, Á.S. Degradation of organic pollutants by heterogeneous electro-Fenton process using Mn-alginate composite. J. Chem. Technol. Biotechnol. 2015, 90, 1439-1447.

17. Hu, X.B.; Deng, Y.H.; Gao, Z.Q.; Liu, B.Z.; Sun, C. Transformation and reduction of androgenic activity of 17 alpha-methyltestosterone in $\mathrm{Fe}_{3} \mathrm{O}_{4} / \mathrm{MWCNTs}_{-} \mathrm{H}_{2} \mathrm{O}_{2}$ system. Appl. Catal. B-Environ. 2012, 127, 167-174.

18. Todd, E. Surface oxidation of pyrite under ambient atmo-spheric and aqueous ( $\mathrm{pH}=2$ to 10) conditions: Electronic structure and mineralogy from X-ray absorption spectroscopy. Geochim. Cosmochim. Acta 2003, 67, 881-893. 
19. Arienzo, M. Oxidizing 2,4,6-trinitroluene with pyrite- $\mathrm{H}_{2} \mathrm{O}_{2}$ suspensions. Chemosphere 1999, 39, $1629-1638$.

20. Che, H.; Bae, S.; Lee, W. Degradation of trichloroethylene by Fenton reaction in pyrite suspension. J. Hazard. Mater. 2011, 185, 1355-1361.

21. Bae, S.; Kim, D.; Lee, W. Degradation of diclofenac by pyrite catalyzed Fenton oxidation. Appl. Catal. B-Environ. 2013, 134, 93-102.

22. Wu, D.L.; Feng, Y.; Ma, L.M. Oxidation of Azo Dyes by $\mathrm{H}_{2} \mathrm{O}_{2}$ in presence of natural pyrite. Water Air Soil. Pollut. 2013, 224, doi:10.1007/s11270-012-1407-y.

23. Zhang, Y.L.; Zhang, K.; Dai, C.M.; Zhou, X.F.; Si, H.P. An enhanced Fenton reaction catalyzed by natural heterogeneous pyrite for nitrobenzene degradation in an aqueous solution. Chem. Eng. J. 2014, 244, 438-445.

24. Wang, C.; Xi, J.Y.; Hu, H.Y. Chemical identification and acute biotoxicity assessment of gaseous chlorobenzene photodegradation products. Chemosphere 2008, 73, 1167-1171.

25. APHA; AWWA; WEF. Standard Methods for the Examination of Water and Wastewater, 20th ed.; APHA/AWWA/WEF: Washington, DC, USA, 1998.

26. Wang, L.S.; Wei, D.B.; Wei, J.; Hu, H.Y. Screening and estimating of toxicity formation with photobacterium bioassay during chlorine disinfection of wastewater. J. Hazard. Mater. 2007, 141, 289-294.

27. Stookey, L.L. Ferrozine-A new spectrophotometric reagent for iron. Anal. Chem. 1970, 42, 779-781.

28. Norwitz, G.; Keliher, P.N. Spectrophotometric determination of aniline by the diazotization-coupling method with $N$-(1-naphthyl) ethylenediamine as the coupling agent. Anal. Chem. 1981, 53, 1238-1240.

29. Stedmon, C.A.; Bro, R. Characterizing dissolved organic matter fluorescence with parallel factor analysis: A tutorial. Limnol. Oceanogr. Methods 2008, 6, 572-579.

30. Baghoth, S.A.; Sharma, S.K.; Amy, G.L. Tracking natural organic matter (NOM) in a drinking water treatment plant using fluorescence excitation-Emission matrices and PARAFAC. Water Res. 2011, 45, 797-809.

31. Li, W.T.; Chen, S.Y.; Xu, Z.X.; Li, Y.; Shuang, C.D.; Li, A.M. Characterization of dissolved organic matter in municipal wastewater using fluorescence PARAFAC analysis and chromatography multi-excitation/emission scan: A comparative study. Environ. Sci. Technol. 2014, 48, 2603-2609.

32. Pignatello, J.J.; Oliveros, E.; MacKay, A. Advanced oxidation processes for organic contaminant destruction based on the Fenton reaction and related chemistry. Crit. Rev. Environ. Sci. Technol. 2006, 36, 1-84.

33. Hashemian, S.; Tabatabaee, M.; Gafari, M. Fenton oxidation of methyl violet in aqueous solution. J. Chem. 2013, 2013, doi:10.1155/2013/509097.

34. Zhang, Y.L.; Zhang K.; Dai, C.M.; Zhou, X.F. Performance and mechanism of pyrite for nitrobenzene removal in aqueous solution. Chem. Eng. Sci. 2014, 111, 135-141.

35. Segura, Y.; Martínez, F.; Melero, J.A.; Fierro, J.L.G. Zero valent iron (ZVI) mediated Fenton degradation of industrial wastewater: Treatment performance and characterization of final composites. Chem. Eng. J. 2015, 269, 298-305. 
36. Moffett, J.W.; Zika, R.G. Reaction kinetics of hydrogen peroxide with copper and iron in seawater. Environ. Sci. Technol. 1987, 21, 804-810.

37. Stumm, W.; James, J. Aquatic Chemistry. An Introduction Empha-Sizing Chemical Equilibria in Natural Waters; John Wiley \& Sons: Michigan, MI, USA, 1981.

38. Pham, A.L.T.; Lee, C.; Doyle, F.M.; Sedlak, D.L. A silica-supported iron oxide catalyst capable of activating hydrogen peroxide at neutral pH values. Environ. Sci. Technol. 2009, 43, 8930-8935.

39. Xue, X.X.; Hanna, K.; Abdelmoula, M.; Deng, N. Adsorption and oxidation of PCP on the surface of magnetite: Kinetic experiments and spectroscopic investigations. Appl. Catal. B-Environ. 2009, $89,432-440$.

40. Kong, L.H.; Hu, X.Y.; He, M.C. Mechanisms of Sb(III) oxidation by pyrite-induced hydroxyl radicals and hydrogen peroxide. Environ. Sci. Technol. 2015, 49, 3499-3505.

41. Kwan, W.P.; Voelker, B.M. Decomposition of hydrogen peroxide and organic compounds in the presence of dissolved iron and ferrihydrite. Environ. Sci. Technol. 2002, 36, 1467-1476.

42. Westerhoff, P.; Chen, W.; Esparza, M. Fluorescence analysis of a standard fulvic acid and tertiary treated wastewater. J. Environ. Qual. 2001, 30, 2037-2046.

43. Goldman, J.H.; Rounds, S.A.; Needoba, J.A. Applications of fluorescence spectroscopy for predicting percent wastewater in an urban stream. Environ. Sci. Technol. 2012, 46, 4374-4381.

44. Stedmon, C.A.; Markager, S.; Bro, R. Tracing dissolved organic matter in aquatic environments using a new approach to fluorescence spectroscopy. Mar. Chem. 2003, 82, 239-254.

45. Bro, R. The N-Way On-Line Course on PARAFAC and PLS. Available online: http://www. models.life.ku.dk/ pih/parafac/chap0contents.htm (accessed on 21 June 2010).

46. Lei, Y.Q.; Wang, G.H.; Guo, P.R.; Li, G.B.; Cai, D.C. The application of three-dimensional fluorescence spectroscopy in the electrochemical degradation of organic pollutions. Chin. J. Anal. Lab. 2014, 33, 373-376. (In Chinese).

(C) 2015 by the authors; licensee MDPI, Basel, Switzerland. This article is an open access article distributed under the terms and conditions of the Creative Commons Attribution license (http://creativecommons.org/licenses/by/4.0/). 